(C) 1984. The Genetical Society of Great Britain

\title{
POLYMORPHISM OF THE TROPICAL BUTTERFLY, DANAUS CHRYSIPPUS L., IN AFRICA
}

\author{
*I. J. GORDON \\ Department of Zoology, University of Cape Coast, Cape Coast, Ghana
}

Received 29.iii.84

\section{SUMMARY}

\begin{abstract}
The polymorphism of Danaus chrysippus is anomalous since it is a distasteful butterfly. In a field study of the B locus polymorphism in Ghana, significant changes in the morph frequencies were recorded over eighteen months at Cape Coast. There were also significant differences between localities. There was some evidence that brown morphs are favoured by wet conditions, and that orange forms have higher survival rates as caterpillars. There were no differences between forms in larval foodplants, sex ratio, body size, wing damage, mating success, or in the effects of weather on adult activity. There was however, strong assortative mating between forms. Crosses with Kenyan females gave aberrant segregations for the sex chromosomes and the $C$ locus. The results are discussed with regard to the hypothesis that polymorphism arose as a result of the overlapping of previously isolated geographical races.
\end{abstract}

\section{INTRODUCTION}

Distasteful species are expected to be monomorphic for colour pattern since rarer morphs are more likely to be predated than commoner forms (Fisher, 1930; Ford, 1964; Turner, 1977). Danaus chrysippus is an undoubtedly distasteful butterfiy (Reichstein et al., 1968; Rothschild et al., 1975; Boppré, 1978) and yet it is polymorphic through large areas of east and central Africa. As many as eight colour pattern morphs occur together in Tanzania (Smith, 1980). Such polymorphism is highly unusual among danaids, which generally conform to expectation in being both distasteful and monomorphic.

Anomalous polymorphisms in aposematic insects are usually explained in one or a combination of three ways: first, by biogeographical history; second, by selective forces other than predation; and third, by special circumstances under which predation may actually promote polymorphism. All three have been invoked for Danaus chrysippus (Owen and Chanter, 1968; Owen, 1970; Edmunds, 1969, 1974; Brower, Edmunds and Moffitt, 1975; Brower et al., 1978; Smith, 1973, 1975a, b, c, 1976a, b, 1979, 1980, 1981). The explanations offered by these authors are plausible, diverse and mutually compatible. Their further evaluation can only proceed on the basis of new data.

The genetic basis of the polymorphism has been most thoroughly investigated by Smith (1975a) who identifies three diallelic loci controlling colour pattern. The A locus controls hindwing colour with an orange/brown being dominant to a white hindwing. The B locus controls the ground colour of

\footnotetext{
* Present address: Dept of Biological Sciences, University of Zimbabwe, PO Box MP 167, Mount Pleasant, Harare, Zimbabwe.
} 
both wings which is either orange or brown with the latter dominant. The $C$ locus controls the apical colour pattern of the forewing, a dominant allele giving a uniform orange or brown colouring and the recessive allele a black apex with a white sub-apical band. Heterozygotes at the $C$ and $A$ loci in Tanzania are recognisable because of minor expression of recessive phenotypes (Smith, 1980). The B and C loci are tightly linked in repulsion with a cross-over value of approximately 1.9 per cent (Smith, 1975a, 1976a). Smith $(1975 b)$ proposes further linkage of the BC loci with an S locus, whose dominant allele suppresses the occurrence of meiotic drive for the $\mathrm{Y}$ chromosome. In the absence of the $\mathrm{S}$ allele, the driving $\mathrm{Y}$ chromosome produces all-female broods (see also Owen and Chanter, 1968).

Independent assortment of the $\mathrm{A}$ and $\mathrm{C}$ loci results in the four named morphs of $D$. chrysippus: dorippus ( $A-C$-), aegyptius ( $A-c c)$, albinus (aaC-) and alcippus (aacc). Through most of west Africa (see maps in Rothschild et al., 1975), the A and C loci are monomorphic for their recessive alleles, while the B locus is polymorphic. Butterflies in this area are therefore either orange or brown alcippus. I here present the results of a field study of the B locus polymorphism in southern Ghana, and of crosses between Ghanaian and Kenyan butterflies. The latter produced some highly unusual segregations with respect to the $\mathrm{C}$ loci and the sex chromosomes. The results are discussed with particular reference to the hypothesis that polymorphism in $D$. chrysippus has resulted from the mixing of previously isolated geographical races (Smith, 1976b, 1980).

\section{Methods}

Sampling was performed at two sites in southern Ghana (Cape Coast and Nungua), approximately 100 miles apart. Habitat descriptions, together with an account of seasonal changes in climate, are provided elsewhere (Gordon, 1982, in prep.).

Adult morph frequencies at the B locus were determined by weekly sampling over an eighteen month period at Akotochir village on the University of Cape Coast campus. Discrimination between orange and brown wings was sometimes difficult with the older specimens, although perfectly obvious when butterflies were fresh. However, of 135 insects each, caught and recorded by two independent observers between April and August 1975, the proportions of browns were 37.8 per cent and 37.0 per cent. It therefore seems that phenotypes were reliably scored.

At Nungua, adults, eggs and caterpillars were sampled intermittently for eight months. Butterflies were captured for chemical analysis and their sex and morph recorded. Immature stages were sampled on each of three food plants (Pergularia daemia Forsk., Calotropis procera Ait., and Leptadenia hastata Pers.). Eggs were normally left on the leaves but all caterpillars were removed and reared in the laboratory. The stage of development (instar 1 to instar 5) at the time of collection was recorded and the wing colours of emergent butterflies noted.

A sample of wild females from Cape Coast was dissected in the laboratory and the number of spermatophores in brown and orange forms were determined. Lastly, a number of caterpillars were collected during a visit to Kenya, reared in Ghana, subsequently crossed with Ghanaian males, and the offspring reared and classified for colour pattern. 


\section{Results}

\section{(i) Adult morph frequencies}

Fig. 1 shows changes in the frequencies of brown butterflies at Cape Coast from March 1975 (when the polymorphism at the B locus was first detected) to August 1976. The frequency of brown butterflies for the entire sample $(N=1485)$ was 33.0 per cent, and ranged from $21 \cdot 2$ per cent (June and July, 1976) to 52.4 per cent (July, 1975). It changed significantly over the eighteen month period $\left(\chi^{2}(17)=44 \cdot 77, P<0 \cdot 001\right)$, but changes between months were only significant for the period March to May 1976. Most changes in frequency were more gradual and alternated with periods of considerable stability (e.g., March-July and August-December 1975). Peaks in the frequencies of browns followed peaks in 1975 rainfall by one month in the major rains and by two months in the minor rains (see data in Gordon, in prep.). The third peak in April 1976 coincided with the onset of the major rains which were unusually early in that year.

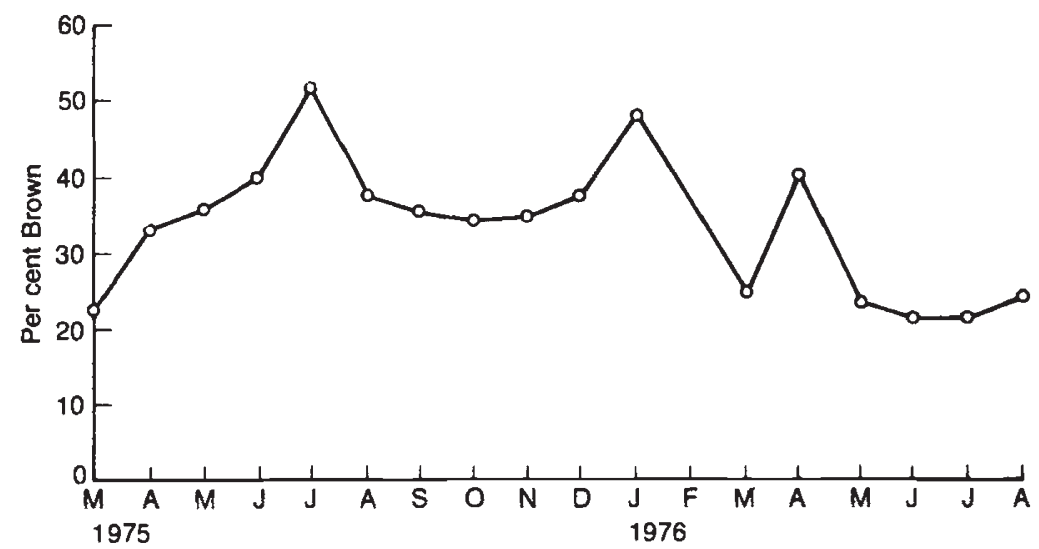

FIG. 1. Monthly changes in morph frequencies at Cape Coast, March 1975-August 1976.

Table 1 shows the frequencies of browns in the adult collections from Nungua. The chi square value for changes between months is just significant but is suspect in view of low expected frequencies for browns in the smaller samples. Its significance is due overwhelmingly to the high frequency of brown butterflies in the July sample. The changes mirror those observed for the equivalent period at Cape Coast in 1975, with browns increasing with the onset of the rains and peaking in July. The overall proportion of browns at Nungua ( 16.2 per cent) is significantly lower than that observed at Cape Coast $\left(33.0\right.$ per cent) $\left(\chi^{2}=29.95, P<0.001\right)$, a result that could be due to the drier conditions in 1983 and at Nungua.

\section{(ii) Activity and the weather}

Differences in wing colour may affect activity levels by altering the degree of reflectance and absorbance of solar radiation (Smith, 1981). In order to investigate this possibility, the Cape Coast data were scanned for examples in which fluctuations in weather conditions occurred between 
TABLE 1

Percentage of brown butterflies in samples of wild adults from Nungua (March-October, 1983)

\begin{tabular}{lrc}
\hline \multicolumn{1}{c}{ Month } & Per cent brown & Sample size \\
\hline March & 18.9 & 74 \\
May & 5.9 & 34 \\
June & 13.2 & 68 \\
July & 32.3 & 31 \\
September & 18.8 & 32 \\
October & 9.1 & 33 \\
Total & 16.2 & 272 \\
\hline \multicolumn{2}{c}{${ }^{2}(5)=10.79, P<0.05$} &
\end{tabular}

successive samples. Specifically, cases were identified in which two hot sunny days were separated in the records by a cool cloudy day or vice-versa. Five such sets were identified as unambiguous examples with respect to the criterion of weather alone (table 2).

TABLE 2

Morph frequencies of butterflies in fluctuating weather conditions at Cape Coast

\begin{tabular}{rrrr}
\hline Date & Weather & Per cent brown & Sample size \\
\hline $16 / 7 / 75$ & CC & $100 \cdot 0$ & 2 \\
$23 / 7 / 75$ & HS & $50 \cdot 0$ & 16 \\
$2 / 8 / 75$ & CC & $33 \cdot 3$ & 9 \\
$6 / 9 / 75$ & HS & $45 \cdot 5$ & 11 \\
$15 / 9 / 75$ & CC & $41 \cdot 7$ & 12 \\
$24 / 9 / 75$ & HS & $25 \cdot 0$ & 16 \\
$12 / 1 / 76$ & HS & $53 \cdot 1$ & 49 \\
$19 / 1 / 76$ & CC & $50 \cdot 0$ & 14 \\
$26 / 1 / 76$ & HS & $28 \cdot 1$ & 32 \\
$11 / 4 / 76$ & HS & $45 \cdot 5$ & 33 \\
$19 / 4 / 76$ & CC & $46 \cdot 2$ & 13 \\
$26 / 4 / 76$ & HS & $30 \cdot 8$ & 26 \\
$21 / 6 / 76$ & HS & $17 \cdot 4$ & 23 \\
$2 / 7 / 76$ & CC & $50 \cdot 0$ & 6 \\
$19 / 7 / 76$ & HS & $13 \cdot 6$ & 22 \\
Totals & HS & $36 \cdot 0$ & 228 \\
& CC & $46 \cdot 4$ & 56 \\
\hline
\end{tabular}

Note. HS means hot sunny, CC means cool cloudy.

Examination of this data suggests that the phenotype at the B locus does not influence activity levels. There are no consistent directions of change in the proportions of browns in response to changes in weather. Neither were the changes between successive samples in each set significant when tested by chi square or (in the case of low expected frequencies) the exact probability test. In view of probable heterogeneity between data sets 
in gene frequencies and weather conditions, the best overall test of the data is obtained by lumping the same-weather samples within each set, and calculating the normal deviate for the chi values from the five $2 \times 2$ tables (Snedecor and Cochran, 1967). The result is non-significant, giving an unweighted deviate of $1.44(0.20>P>0.10)$ and a weighted deviate of 1.16 $(0.40>P>0 \cdot 20)$. It should be noted that the same data set revealed a consistent lowering of the sex ratio (per cent male) during cool weather and significant differences in overall sex ratios under cloudy and sunny conditions (Gordon, in prep.). Weather was therefore exerting a detectable effect on activity levels, but it appears that the effect was the same for both orange and brown butterflies.

\section{(iii) Survival in the immature stages}

Table 3 shows the frequencies of brown butterflies reared from wild caterpillars collected at Nungua. The tendency for browns to be less well represented in the later instars is not significant if chi square is calculated for four degrees of freedom $\left(\chi^{2}(4)=9.05,0.10>P>0.05\right)$. However, this result is suspect due to small expected frequencies of browns in the fourth and fifth instars. If the latter two stages are combined, the tendency is significant $\left(\chi^{2}(3)=8 \cdot 71, P<0.05\right)$, and is even more so if the second and third instars are also amalgamated $\left(\chi^{2}(2)=8.65, P<0.02\right)$. The results thus suggest that there is selection against browns in the caterpillar stage.

TABLE 3

Percentage of brown butterflies in samples reared from caterpillars of different ages when collected at Nungua

\begin{tabular}{lcc}
\hline Instar & Per cent brown & Sample size \\
\hline First & $17 \cdot 1$ & 123 \\
Second & $8 \cdot 5$ & 94 \\
Third & $10 \cdot 5$ & 57 \\
Fourth & $3 \cdot 2$ & 31 \\
Fifth & $0 \cdot 0$ & 15 \\
\hline
\end{tabular}

Notes. $\chi^{2}(4)=9 \cdot 05,0 \cdot 10>P>0.05$.

$\chi^{2}(3)=8 \cdot 71, P<0 \cdot 05$, lumping fourth and fifth instars.

$\chi^{2}(2)=8.56, P<0.02$, lumping

fourth and fifth,

and second and third instars.

\section{(iv) Non-random mating}

Table 4 gives the numbers of like and unlike matings between phenotypes that were recorded during the field sampling at Cape Coast. The data show a significant deficit of unlike matings, suggesting the occurrence of strong assortative mating for B locus phenotypes.

Table 5 compares the mating success of brown and orange males and females and shows that neither form enjoys a mating advantage. This conclusion is confirmed for the female sex by table 6 which compares the numbers of spermatophores in brown and orange forms. 
TABLE 4

Numbers of like and unlike matings between B locus phenotypes in natural populations at Cape Coast

\begin{tabular}{|c|c|c|c|c|}
\hline & & \multicolumn{2}{|c|}{ Females } & \multirow[b]{2}{*}{ Totals } \\
\hline & & Orange & Brown & \\
\hline \multirow{3}{*}{ Males } & Orange & 12 & 2 & 14 \\
\hline & Brown & 1 & 5 & 6 \\
\hline & Totals & 13 & 7 & 20 \\
\hline
\end{tabular}

Note. By exact probability test, $P=0 \cdot 007$.

TABle 5

Numbers of $B$ locus phenotypes caught mating and unmated in selected samples at Cape Coast

\begin{tabular}{|c|c|c|c|c|c|c|c|c|}
\hline & \multicolumn{2}{|c|}{ Males } & \multirow[b]{2}{*}{ Totals } & \multirow[b]{2}{*}{$x^{2}$} & \multicolumn{2}{|c|}{ Females } & \multirow[b]{2}{*}{ Totals } & \multirow[b]{2}{*}{$x^{2}$} \\
\hline & Brown & Orange & & & Brown & Orange & & \\
\hline $\begin{array}{l}\text { Mated } \\
\text { Unmated }\end{array}$ & $\begin{array}{r}6 \\
61\end{array}$ & $\begin{array}{r}14 \\
156\end{array}$ & $\begin{array}{r}20 \\
217\end{array}$ & 0.001 & $\begin{array}{r}7 \\
28\end{array}$ & $\begin{array}{l}13 \\
86\end{array}$ & $\begin{array}{r}20 \\
114\end{array}$ & 0.496 \\
\hline Totals & 67 & 170 & 237 & & 35 & 99 & 134 & \\
\hline
\end{tabular}

Note. Only samples in which matings were observed are included.

TABLE 6

Numbers of spermatophores in brown and orange females collected from the field at Cape Coast

\begin{tabular}{lllllll}
\hline & \multicolumn{5}{c}{ No. of spermatophores } & \\
\cline { 2 - 5 } Morph & 0 & 1 & 2 & 3 & 4 & Sample size \\
\hline Brown & 3 & 4 & 8 & 3 & 0 & 18 \\
Orange & 5 & 19 & 11 & 4 & 1 & 40 \\
Totals & 8 & 23 & 19 & 7 & 1 & 58 \\
& $\chi^{2}(2)$ & $=3 \cdot 35,0.30>P>0.20$ & \\
\hline
\end{tabular}

Note. Butterflies with 2 or more spermatophores are lumped together for the chi square test.

(v) Larval foodplants, sex ratios, body size and wing damage

Table 7 shows that there are no differences between the two morphs in larval foodplants, sex ratio, body size or wing damage.

\section{(vi) Segregations in Ghana-Kenya crosses}

Table 8 shows the results for the $A$ and $C$ loci of crosses between Ghanaian males and Kenyan females. Two of these crosses produced all-female broods (KG1 and KG3), presumably as a result of the presence 
TABLE 7

Larval foodplant, sex ratios, body sizes and wing damage in brown and orange butterflies from Nungua and Cape Coast

\begin{tabular}{|c|c|c|c|}
\hline $\begin{array}{l}\text { Larval foodplants (Nungua) } \\
\% \text { reared from collections on: }\end{array}$ & Brown & Orange & $\begin{array}{l}\text { Statistical } \\
\text { test }\end{array}$ \\
\hline C. procera (129) & $10 \cdot 9$ & $89 \cdot 1$ & \\
\hline P. daemia (127) & $11 \cdot 0$ & $89 \cdot 0$ & \\
\hline L. hastata (64) & $12 \cdot 5$ & $87 \cdot 5$ & \\
\hline \multicolumn{4}{|l|}{ Sex ratios (Cape Coast) } \\
\hline$\%$ male & $57 \cdot 8(493)$ & $61 \cdot 6(992)$ & $\chi^{2}=1 \cdot 82, \mathrm{NS}$ \\
\hline \multicolumn{4}{|l|}{ Body size (Cape Coast) } \\
\hline Forewing length $(\mathrm{cm}): \underset{\text { female }}{\text { male }}$ & $\begin{array}{l}3 \cdot 58(79) \\
3 \cdot 70(96)\end{array}$ & $\begin{array}{l}3.55(165) \\
3.70(216)\end{array}$ & $d=0.97, \mathrm{NS}$ \\
\hline \multicolumn{4}{|l|}{ Wing damage (Cape Coast) } \\
\hline$\%$ with wing damage & $22 \cdot 8(491)$ & $24 \cdot 5(986)$ & $\chi^{2}=0.46, \mathrm{NS}$ \\
\hline
\end{tabular}

Note. NS means not significant. No test is applied where there is obviously no difference. Sample sizes are given in brackets.

TABLE 8

Morph frequencies in the offspring of crosses between Kenyan females and Ghanaian males

\begin{tabular}{|c|c|c|c|c|c|c|}
\hline \multirow[b]{2}{*}{ Brood No. } & \multicolumn{2}{|c|}{ Female parent } & \multicolumn{3}{|c|}{ Offspring phenotypes } & \multirow[b]{2}{*}{$N$} \\
\hline & Phenotype & Genotype & alcippus & dorippus & aegyptius & \\
\hline KGl & albinus & $a a C c$ & $0: 26$ & $0: 0$ & $0: 0$ & 26 \\
\hline $\mathrm{KG} 2$ & dorippus & $A A C c$ & $0: 0$ & $19: 0$ & $0: 16$ & 35 \\
\hline KG3 & dorippus & $A a C c$ & $0: 5$ & $0: 2$ & $0: 11$ & 18 \\
\hline KG4 & dorippus & $A A C C$ & $0: 0$ & $6: 6$ & $4: 4$ & 20 \\
\hline
\end{tabular}

Notes. All male parents were alcippus (aacc). Female genotypes are inferred from the phenotype frequencies in the offspring. Phenotype frequencies are given as male: female.

of driving $\mathrm{Y}$ chromosomes in the Kenyan stock. Segregation at the A locus was apparently normal, although that in $\mathrm{KG} 3$ is not a good fit to the expected $1: 1$ ratio $\left(\chi^{2}=3.56,0 \cdot 10>P>0.05\right)$.

At the $C$ locus however, segregation was aberrant in all but brood KG4. In $\mathrm{KG1}$, the dominant forewing phenotype failed to appear in the offspring despite its expression in the female parent. Reversed dominance can be ruled out as an explanation since dominance was normal in the remaining broods. The female parent must therefore have been a heterozygote, and the results could be due either to the selective deaths of albinus (aaCc) zygotes or larvae, or to meiotic drive for the $b c$ chromosome (all offspring were orange). Autosomal drive for the $b C$ chromosome has previously been suggested to explain aberrant segregations in Tanzanian D. chrysippus (Smith, 1976a).

In $\mathrm{KG} 2$, the $C$ chromosome must have segregated with the $\mathrm{X}$ chromosome and that carrying the $c$ allele with the Y chromosome. Smith (1976a) suggested that the two homologous pairs may not always assort independently since the aberrant segregations he observed at the $\mathrm{BC}$ loci all occurred in all female broods. This result confirms his suspicion. It also lends support 
to the meiotic drive theory for KGl since identical nonrandom assortment would automatically produce drive for the $c$ allele in the presence of the driving Y chromosome.

In KG3, the presence of both forewing phenotypes amongst the offspring means that the female parent must have been a heterozygote. There is therefore a significant deficiency of $C c$ genotypes $\left(\chi^{2}=10.89, P<0.001\right)$. The selective elimination of $a a C c$ genotypes would explain both this deficiency and the poor fit of the backcross hypothesis for the A locus noted above. This brood is therefore consistent with the selective mortality hypothesis for KGl.

\section{Discussion}

Polymorphism at the $\mathrm{B}$ locus presents less of a challenge to aposematic logic than does that at the $A$ and $C$ loci since its effect on colour pattern is so much less. It is unlikely that predators will discriminate between $B$ locus phenotypes when the $\mathrm{A}$ and $\mathrm{C}$ loci are monomorphic. No differences in wing damage were detected between brown and orange butterflies at Cape Coast, a result that suggests the absence not only of selective predation but also of differences in longevity.

Nonetheless, morph frequencies underwent significant change over an eighteen month period at Cape Coast. The changes were mostly gradual with values at the end similar to those at the beginning of sampling. It is not clear what factors were responsible, although an association between high frequencies of browns and wet conditions is suggested by the major rainy season data for Cape Coast in 1975 and Nungua in 1983, and by the lower frequencies of browns in the latter (drier) area. This seasonality is, however, less obvious in 1976 when browns peaked as the rains started and declined as conditions got wetter. A more extended sampling period is necessary to establish seasonal patterns.

A possible basis for seasonal selection is provided by the evidence for selection against browns in the caterpillar stage. This evidence is based largely on samples collected during a particularly severe dry seăson. Ninetytwo per cent of the caterpillars in table 3 were collected before the rains began in May. Most caterpillars collected during and after the rains were parasitised or diseased (Gordon, in prep.), so that the sample of emergent butterflies for this period is too small to test for an improvement in the survival of browns.

No balancing selection in favour of browns was detected in this study. No differences were found between forms in their activity levels in varying weather conditions, in sex ratios, in body size, in mating success or in larval foodplants. It may be that some of the observed changes in morph frequencies were due to migratory movements rather than local selection. $D$. chrysippus is migratory, and there were strong differences in the proportion of brown butterflies between Cape Coast and Nungua. East-west shifts in monarch populations could have produced the changes shown in fig. 1 . On the other hand, there was considerable stability during times of rapid population change (e.g., August-December, 1975: see population data in Gordon, in prep.) when migratory movements might be expected.

A major behavioural difference exists between the two forms in their mating preferences: strong assortative mating occurs at the $\mathrm{B}$ locus. 
However, such mating has no effect on gene frequencies unless:

(a) it is complete and speciation results;

(b) mate scarcity puts the rarer form at a disadvantage;

(c) it is combined with other differences in fitness between the three genotypes.

The first two possibilities are excluded by the data in tables 4 to 6 , but not the third. Assortative mating increases homozygosity, especially for the recessive allele (Crow and Kimura, 1970), so that at least part of the high frequency of orange butterflies is attributable to this factor. If $B b$ genotypes are the least fit, then assortative mating will help to prevent the loss of the rarer allele that is the theoretical consequence of heterozygote disadvantage. It could in this way contribute to stabilising the polymorphism.

Smith (1984) reports similar assortative mating at the B locus in Tanzania. This suggests that it may be continent-wide in its occurrence. The mechanisms involved would be worth investigating: analysis of male pheromones from Tanzanian monarchs revealed no differences between morphs (Smith, 1981). Equally interesting is the question of why it occurs. It may be fortuitous or adaptive. In either case, it suggests a period of racial isolation in the past. Currently, the B locus seems to be monomorphic for the $b$ allele in north-east Africa and for $B$ in west-central and south-west Africa (Smith, 1980). Such a distribution pattern could be the result of morph ratio clines, but the discovery of assortative mating at this locus strengthens the case for a history of allopatry.

On the basis of the current distribution of the four named morphs of D. chrysippus, Smith $(1976 b, 1980)$ suggested that the polymorphism of the $\mathrm{A}$ and $\mathrm{C}$ loci arose during Pleistocene isolation between a brown aegyptius race in the south, an orange dorippus race in the north-east, and a mixed brown and orange alcippus race in the west. If the B locus polymorphism owes its origin to the same episode of isolation, then the western race must have been pure orange or brown. Its present mixed status would then be due to a more rapid or less restricted spread of the invading allele at the B locus following the breakdown of isolation. Alternatively, there may have been more than one episode of isolation and subsequent mixing between butterfly populations.

Further support for an allopatric interpretation of the origin of polymorphism in $D$. chrysippus comes from a consideration of the distribution and occurrence of all-female broods. They are now known from Uganda (Owen and Chanter, 1968), Tanzania (Smith, 1975b), and Kenya (D. Schneider and M. Boppre, 1976, in litt. to D. A. S. Smith pers. comm.; this paper), but appear to be absent in west Africa (Chanter and Owen, 1972; Edmunds, 1976; Gordon, in prep.). They may be a consequence of racial mixing in east and central Africa, in which case their absence is also predicted for the southern and north-eastern populations in which the $\mathrm{C}$ and $\mathrm{A}$ loci are monomorphic. It is interesting in this context that they occur with different frequencies in the aegyptius and dorippus morphs in Tanzania. Their significantly lower incidence in dorippus led Smith to propose coupling linkage between the C and S loci (Smith, 1975b). If Smith's model for meiotic drive and its suppression is correct, then the driving $Y$ chromosome may have originated in the north eastern dorippus race where its presence would have selected for the $S$ allele. 
This hypothesis leaves the proposed linkage between $C$ and $S$ unexplained, except as a matter of chance. As danaids may have around 30 haploid chromosomes (Robinson, 1971), an appeal to chance is somewhat unsatisfactory. An alternative possibility is that non-random assortment of chromsomes commonly occurs in areas of racial mixing. This is an unorthodox suggestion but brood KG2 provides direct evidence that assortment can be non-random in Kenya. Smith (1975a) aiso considered non-random assortment as a possible explanation of aberrant segregations observed in Tanzania, although he preferred an hypothesis invoking independent autosomal drive.

From whatever perspective the matter is viewed, there is no denying that some odd genetic events take place in the populations of $D$. chrysippus which are polymorphic. That they are due to racial mixing is a useful working hypothesis since it predicts their absence in areas where this butterfly is monomorphic. This prediction is open to immediate test with respect to the occurrence of all-female broods.

Acknowledgments. I thank Henry Davis and Lorna Depew for assistance in the field, $\mathrm{Mr}$ J. W. Crentsil for spermatophore data, the University of Cape Coast for facilities and for funding my trip to Kenya, Mr C. W. Agyakwah for identifying the plants, and Denis Owen, David Smith, Malcolm Edmunds and Tim Shreeve for comments on earlier versions of this paper. I also thank Derek Whitely for drawing the figure, and the British Council for financial support. This paper was prepared during tenure of a CICHE Resettlement Fellowship at Oxford Polytechnic.

\section{REFERENCES}

BOPPRÉ, M. 1978. Chemical communication, plant relationships and mimicry in the evolution of danaid butterflies. Entomol. Exp. Appl., 24, 264-277.

BROWER. L. P., EDMUNDS, M. AND MOFFITT, C. M. 1975. Cardenolide content and palatability of a population of Danaus chrysippus butterflies from West Africa. J. Entomol. A, 49, 183-196.

BROWER, L. P., GIBSON, D. O., MOFFITT, C. M. AND PANCHEN, A. L. 1978. Cardenolide content of Danaus chrysippus butterflies from three areas of east Africa. Biol. J. Linn. Soc., 10, 251-273.

CHANTER, D. O. AND OWEN, D. F. 1972. The inheritance and population genetics of sex ratio in the butterfly, Acraea encedon. J. Zool. Lond., 166, 363-383.

CROW, J. F. AND KIMURA, M. 1970. An Introduction to Population Genetics Theory. Harper \& Row, New York.

EDMUNDS, M. 1969. Polymorphism in the mimetic butterfly Hypolimnas misippus L. in Ghana. Heredity, 24, 281-302.

EDMUNDS, M. 1974. Defense in Animals. Longmans, Harlow, Essex.

EDMUNDS, M. 1976. Larval mortality and population regulation in the butterfly Danaus chrysippus in Ghana. Zool. J. Linn. Soc., 58, 129-145.

FISHER, R. A. 1930. The Genetical Theory of Natural Selection. Clarendon Press, Oxford.

FORD, E. B. 1964. Ecological Genetics. First Edition. Methuen, London.

GORDON, I. J. 1982. The Biology of Danaus chrysippus (Lepidoptera, Danaidae) and its Mimics in Ghana. PhD thesis. University of Ghana.

OWEN, D. F. 1970. Mimetic polymorphism and the palatability spectrum. Oikos, 21, 333-336. OWEN, D. F. AND CHANTER, D. O. 1968. Population biology of tropical African butterflies. 2. Sex ratio and polymorphism in Danaus chrysippus L. Revue Zool. Bot. afr., 78, 81-97.

REICHSTEIN, T., VON EUW, J., PARSONS, J. A. AND ROTHSCHILD, M. 1968. Heart poisons in the monarch butterfly. Science, 161, 861-866.

ROBINSON, R. 1971. Lepidoptera Genetics. Pergamon Press, Oxford.

ROTHSCHILD, M., VON EUW, J., REICHSTEIN, J., SMITH, D. A. S. AND PIERRE, J. 1975. Cardenolide storage in Danaus chrysippyus (L.) with additional notes on $D$. plexippus (L.). Proc. Roy. Soc., B., 190, 1-31. 
SMITH, D. A. S. 1973. Negative non-random mating in the polymorphic butterfly Danaus chrysippus in Tanzania. Nature, 242, 131-132.

SMITH, D. A. S. $1975 a$. Genetics of some polymorphic forms of the African butterfly Danaus chrysippus L. (Lepidoptera: Danaidae). Ent. Scand., 6, 134-144.

SMITH, D. A. S. 1975 b. All-female broods in the polymorphic butterfly Danaus chrysippus L. and their ecological significance. Heredity, 34, 363-371.

SMITH, D. A. S. $1975 \mathrm{c}$. Sexual selection in a wild population of the butterfly Danaus chrysippus L. Science, $187,664-665$.

SMITH, D. A. S. $1976 a$. Evidence for autosomal meiotic drive in the butterfly Danaus chrysippus L. Heredity, 36, 139-142.

SMITH, D. A. S. $1976 b$. Phenotypic diversity, mimicry and natural selection in the African butterfly Hypolimnas misippus L. (Lepidoptera: Nymphalidae). Biol. J. Linn. Soc., 8, 183-204.

SMITH, D. A. S. 1979. The significance of beak marks on the wings of an aposematic, distasteful and polymorphic butterfly. Nature, 281, 215-216.

SMITH, D. A. S. 1980. Heterosis, epistasis and linkage disequilibrium in a wild population of the polymorphic butterfly Danaus chrysippus (L.). Zool. J. Linn. Soc., 69, 87-109.

SMITH, D. A. S. 1981. Heterozygous advantage expressed through sexual selection in a polymorphic African butterfly. Nature, 289, 174-175.

SMITH, D. A. S. 1984. In Vane-Wright, R. I. and Ackery, P. R. (eds), The Biology of Butterflies. Symp. Roy. Ent. Soc., Lond., Academic Press, London. (In press.)

SNEDECOR, G. W. AND COCHRAN, w G. 1967. Statistical Methods, 6th ed., Ames, Iowa State University Press.

TURNER, J. R. G. 1977. Butterfly mimicry: the genetical evolution of an adaptation. Evol. Biol., $10,163-206$. 